\title{
Association between the Val34Leu polymorphism in blood coagulation factor XIII-A and intracerebral hemorrhage: a meta-analysis
}

\author{
X. Ye ${ }^{1}$ and B. $\mathrm{Ye}^{2}$ \\ ${ }^{1}$ Department of Neurosurgery, \\ Xiasha Branch of Affiliated Sir Run Run Shaw Hospital, Hangzhou, \\ Zhejiang, China \\ ${ }^{2}$ Department of Thoracic Surgery, Hangzhou Red Cross Hospital, \\ Hangzhou, Zhejiang, China \\ Corresponding author: B. Ye \\ E-mail: yebomed@126.com
}

Genet. Mol. Res. 15 (3): gmr.15038327

Received December 22, 2015

Accepted June 8, 2016

Published July 25, 2016

DOI heep://dx.doi.org/10.4238/gmr.15038327

Copyright (C) 2016 The Authors. This is an open-access article distributed under the terms of the Creative Commons Attribution ShareAlike (CC BY-SA) 4.0 License.

\begin{abstract}
Although the Val34Leu polymorphism in blood coagulation factor XIII-A (FXIII-A) has been implicated in the pathogenesis of intracerebral hemorrhage (ICH), the results of research conducted thus far have been inconclusive. In this metaanalysis, we have assessed the association between the FXIII-A Val34Leu polymorphism and ICH risk. Published reports pertaining to this association were retrieved from the PubMed database, and the data from these studies were pooled and statistically analyzed with Stata 12.0. Summary odds ratios (OR) and 95\% confidence intervals $(95 \% \mathrm{CI})$ were calculated according to a fixed-effect or a random-effect model (as appropriate). The initial search identified 520 articles, only seven of which (retrospective studies) met the inclusion criteria and
\end{abstract}


were included in this meta-analysis. These studies comprised $727 \mathrm{ICH}$ patients and 1968 controls. The results of a combined analysis showed no significant association between the FXIII-A Val34Leu polymorphism and $\mathrm{ICH}$ risk in the overall population ( $\mathrm{Leu} / \mathrm{Leu} v s \mathrm{Val} / \mathrm{Val}: \mathrm{OR}=1.41$, $95 \% \mathrm{CI}=0.82-2.43 ; \mathrm{Val} / \mathrm{Leu} v \mathrm{Val} / \mathrm{Val}: \mathrm{OR}=1.08,95 \% \mathrm{CI}=0.89-1.30$; dominant model: $\mathrm{OR}=1.14,95 \% \mathrm{CI}=0.95-1.36$; recessive model: $\mathrm{OR}$ $=0.72,95 \% \mathrm{CI}=0.43-1.22)$. The results of this meta-analysis suggest that the FXIII-A Val34Leu polymorphism is not associated with ICH risk in a Caucasian population. Further large and well-designed studies must be conducted to confirm this preliminary conclusion.

Key words: Blood coagulation factor; Val34Leu polymorphism; Intracerebral hemorrhage

\section{INTRODUCTION}

Stroke is the second leading cause of death after ischemic heart disease, and is the main cause of acquired disability worldwide (Feigin et al., 2009). Strokes are generally classified as ischemic or hemorrhagic, and spontaneous intracerebral hemorrhage (ICH) is the most common form of hemorrhagic stroke (Qureshi et al., 2009). A recent large cohort study found that the major risk factors for ICH included advanced age, the African-American ethnicity, hypertension, lower low density lipopolysaccharide cholesterol levels, and lower triglyceride content (Sturgeon et al., 2007). The incidence of ICH is expected to rise over the coming years, primarily because of the ageing populations of developed countries and widespread use of antithrombotic therapy in the elderly (Lovelock et al., 2007). However, while some individuals exposed to these risk factors do not develop the disease, several ICH patients are not susceptible to the known risk factors. Epidemiological data have shown that genetic factors play an important role in the progression of ICH (Jagieła et al., 2014; Woo et al., 2014). This suggested that genetic polymorphisms could induce differences in the ICH risk between individuals.

Blood coagulation factor XIII (FXIII) is the last enzyme affecting the final stages of the coagulation cascade (Perez et al., 2011). Biochemically, FXIII is an inactive enzyme precursor, containing two A subunits that form the active site, and two B subunits that protect the A subunit from proteolytic degradation and non-proteolytic activation in the plasma (Wells et al., 2006). FXIII is believed to play a vital role in endothelial homeostasis in the brain; this is because homozygous FXIII deficiency is reported to be correlated with a $25-60 \%$ risk of ICH (Nugent, 2006; Hsieh and Nugent, 2008). The gene coding for the A subunit of FXIII, located on chromosome 6 (p24-p25), comprises $160 \mathrm{~kb}$ and 15 exon regions (Wang et al., 2014). The FXIII Val34Leu variant is a G-to-T point mutation in exon 2 of the gene, resulting in a valine (Val) to leucine (Leu) substitution at amino acid 34 (Mikkola et al., 1994). Previous meta-analyses have indicated that the FXIII-A Val34Leu polymorphism may protect humans against coronary artery disease and venous thromboembolism (Wells et al., 2006; Vokó et al., 2007), but not ischemic stroke (Li et al., 2012).

Several studies conducted over the past decade have suggested that the FXIII-A Val34Leu polymorphism is associated with ICH susceptibility. However, the results of these studies remain controversial, possibly because of their small sample sizes, low statistical power,

Genetics and Molecular Research 15 (3): gmr.15038327 
and clinical heterogeneity (Ammar et al., 2012). Therefore, this meta-analysis was conducted to assess the relationship between the FXIII-A Val34Leu polymorphism and ICH risk.

\section{MATERIAL AND METHODS}

\section{Study selection}

Studies reporting on the correlation between the FXIII-A Val34Leu polymorphism and ICH up to November 2015 were identified on the PubMed database using the following search terms and their combinations: "intracerebral hemorrhage", "factor XIII/FXIII", "Val34Leu", and "polymorphism". Potentially relevant studies were further identified from the reference lists of articles included after a thorough review of the title, abstract, and full text. The search was performed without any restrictions on the language and was focused on studies conducted in humans.

\section{Inclusion and exclusion criteria and data extraction strategy}

Studies meeting the following criteria were included in this study: 1) studies that evaluated the association between the FXIII-A Val34Leu polymorphism and ICH; 2) casecontrol studies; and 3) studies providing the genotype frequencies of cases and controls (or those wherein the genotype frequencies could be calculated from data provided in the text). Studies meeting the following criteria were excluded from our analysis: 1) case reports, letters, reviews, meta-analyses, and editorial articles; 2) studies lacking case controls in evaluation of the association between the FXIII-A Val34Leu polymorphism and ICH risk; 3) reports in which the number of null and wild genotypes could not be ascertained; and 4) studies with duplicate data. The available data were independently extracted from each study by two investigators according to the inclusion criteria listed above. The following data were collected from each study: the name of the first author, year of publication, country of origin, ethnicity, area, number of patients and controls, genotype and allele distributions at the polymorphic site, and evidence of Hardy-Weinberg equilibrium (HWE; Table 1). When the two investigators could not reach a consensus, an expert was consulted to resolve the dispute, and a final majority decision was taken.

\begin{tabular}{|c|c|c|c|c|c|c|c|c|c|c|c|}
\hline \multirow[t]{2}{*}{ First author } & \multirow[t]{2}{*}{ Year } & \multirow[t]{2}{*}{ Area } & \multirow[t]{2}{*}{ Ethnicity } & \multirow[t]{2}{*}{ Cases/controls } & \multicolumn{3}{|c|}{ Patient genotypes } & \multicolumn{3}{|c|}{ Control genotypes } & \multirow[t]{2}{*}{ HWE test } \\
\hline & & & & & $\mathrm{Val} / \mathrm{Val}$ & $\mathrm{Val} /$ Leu & Leu/Leu & $\mathrm{Val} / \mathrm{Val}$ & $\mathrm{Val} /$ Leu & Leu/Leu & \\
\hline Corral & 2000 & Spain & Caucasian & $116 / 465$ & 78 & 32 & 6 & 301 & 150 & 14 & 0.36 \\
\hline Gemmati & 2001 & Italy & Caucasian & $130 / 200$ & 59 & 54 & 17 & 114 & 73 & 13 & 0.78 \\
\hline Reiner & 2001 & Holland & Caucasian & $42 / 345$ & 25 & 15 & 2 & 190 & 131 & 24 & 0.83 \\
\hline Endler & 2003 & Austria & Caucasian & $94 / 369$ & 50 & 37 & 7 & 192 & 145 & 32 & 0.54 \\
\hline Slowik & 2005 & Poland & Caucasian & $64 / 127$ & 32 & 28 & 4 & 54 & 60 & 13 & 0.54 \\
\hline Ladenvall & 2009 & Sweden & Caucasian & $183 / 364$ & 89 & 81 & 13 & 210 & 130 & 24 & 0.53 \\
\hline Antalfi & 2012 & Hungary & Caucasian & $98 / 98$ & 49 & 30 & 19 & 56 & 38 & 4 & 0.43 \\
\hline
\end{tabular}

$\mathrm{HWE}=$ Hardy-Weinberg equilibrium.

\section{Statistical analysis}

The conformance of the genotype frequencies of controls with the HWE was confirmed by the $\chi^{2}$ test. The strength of the association between the FXIII-A Val34Leu polymorphism 
and ICH was measured by odds ratios (OR) with $95 \%$ confidence intervals (CI) under a codominant model (Val/Leu vs $\mathrm{Val} / \mathrm{Val}$; Leu/Leu vs $\mathrm{Val} / \mathrm{Val})$, a dominant model (Val/Leu+Leu/ Leu $v s \mathrm{Val} / \mathrm{Val})$, and a recessive model (Leu/Leu $v s \mathrm{Val} / \mathrm{Leu}+\mathrm{Val} / \mathrm{Val})$. Heterogeneity among studies was assessed using the $I^{2}$ statistics (Lau et al., 1997), where $I^{2}$ values of 25, 50, and $75 \%$ were defined as low, moderate, and high estimates, respectively. In case of heterogeneity among the studies, the pooled OR was estimated using the fixed-effects model $\left(\mathrm{P}>0.10\right.$ or $I^{2}<$ $50 \%$ ). Otherwise, the random-effects model was used to estimate the pooled OR. A cumulative meta-analysis was conducted to provide a framework for updating the genetic effect of all studies, to measure the change in genetic effect with the accumulation of evidence, and to identify the trend in the estimated risk effect (Zintzaras and Lau, 2008). Publication bias was analyzed by a regular funnel plot as well as a Begg's funnel -plot $(\mathrm{P}<0.05$ was considered statistically significant). All analyses were performed using the Stata software package (v.12.0; Stata Corporation, College Station, TX, USA).

\section{RESULTS}

\section{Eligible studies}

Our initial search identified 520 studies based the search terms. Screening of the study titles and abstracts resulted in the exclusion of 511 articles; the 9 remaining articles (Catto et al., 1998; Corral et al., 2000; Gemmati et al., 2001; Reiner et al., 2001; Cho et al., 2002; Endler et al., 2003; Slowik et al., 2005; Ladenvall et al., 2009; Antalfi et al., 2013) were subjected to a full publication review. Two of these articles were excluded (Catto et al., 1998; Cho et al., 2002). Figure 1 is a flow chart depicting the search strategy and study selection criteria. The complete dataset included 1968 controls and 727 patients with primary ICH. The studies were published between 2000 and 2015. The selected articles were written in English, and the genotype distribution in the controls was consistent with the HWE for all selected studies. The included ICH cases and control subjects were of Caucasian ethnicity. The characteristics of the included studies are summarized in Table 1.

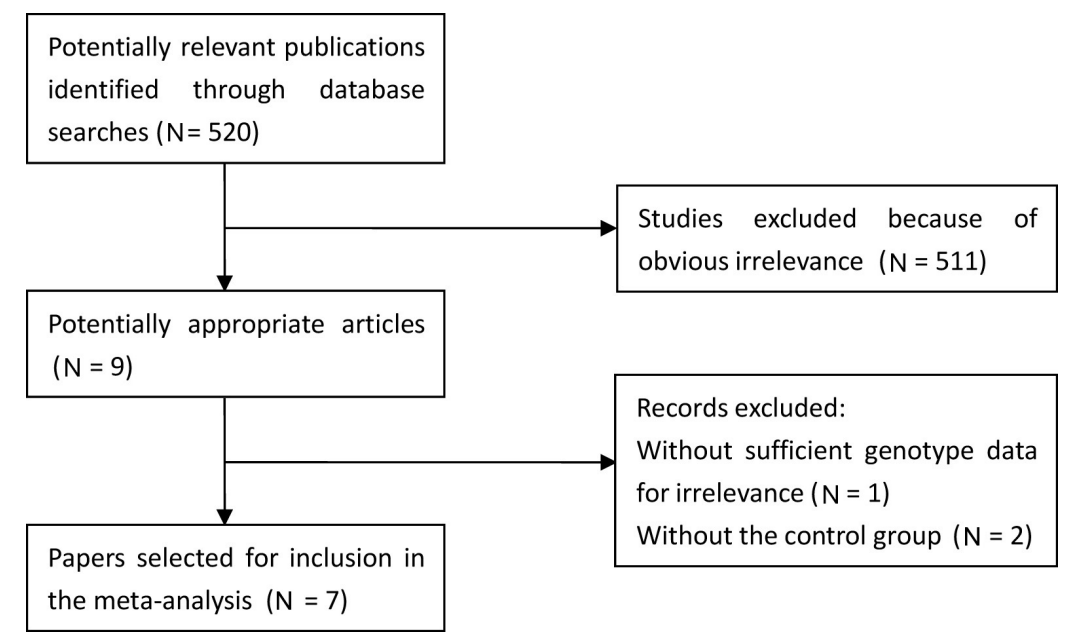

Figure 1. Flow chart depicting the study identification process.

Genetics and Molecular Research 15 (3): gmr.15038327 


\section{Meta-analysis}

Meta-analysis of the pooled data from all seven studies revealed significant heterogeneity in the Leu/Leu vs Val/Val and the recessive genetic comparison model. Therefore, the random-effect model was used to pool the results of these two models (Figures 2-5). The results of this meta-analysis are summarized in Table 2. The results showed that the FXIII-A Val34Leu polymorphism is not associated with increased ICH risk in any of the genetic models $\left(\mathrm{Leu} / \mathrm{Leu} v_{s} \mathrm{Val} / \mathrm{Val}: \mathrm{OR}=1.41,95 \% \mathrm{CI}=0.82-2.43 ; \mathrm{Val} / \mathrm{Leu} v s \mathrm{Val} / \mathrm{Val}\right.$ : $\mathrm{OR}=1.08,95 \% \mathrm{CI}=0.89-1.30$; dominant model: $\mathrm{OR}=1.14,95 \% \mathrm{CI}=0.95-1.36$; recessive model: $\mathrm{OR}=0.72,95 \% \mathrm{CI}=0.43-1.22)$. The cumulative meta-analysis revealed no obvious association between the FXIII-A Val34Leu polymorphism and ICH risk (Figure 6).

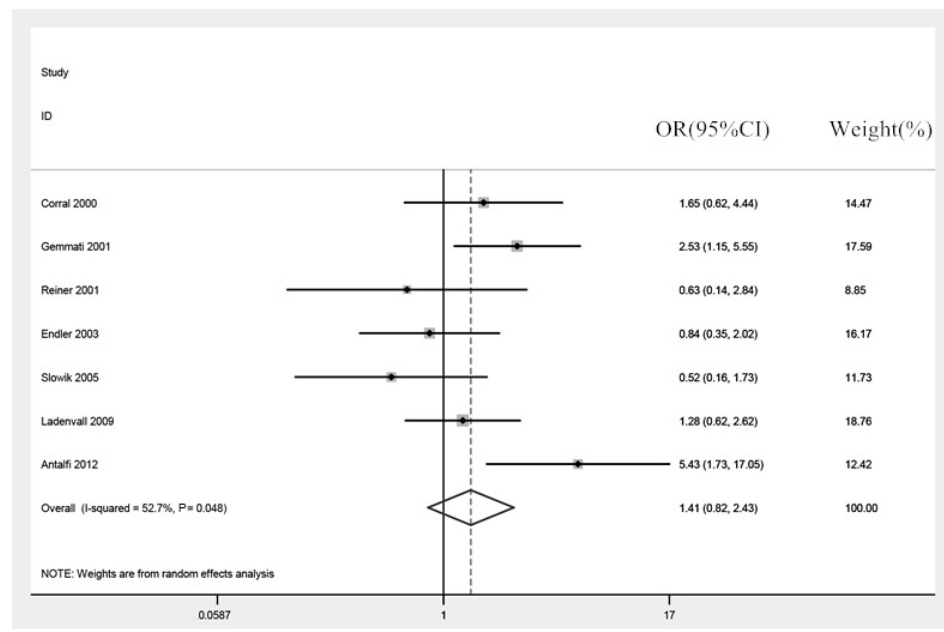

Figure 2. Association between the FXIII-A Val34Leu polymorphism and intracerebral hemorrhage risk (Leu/Leu vs $\mathrm{Val} / \mathrm{Val})$.

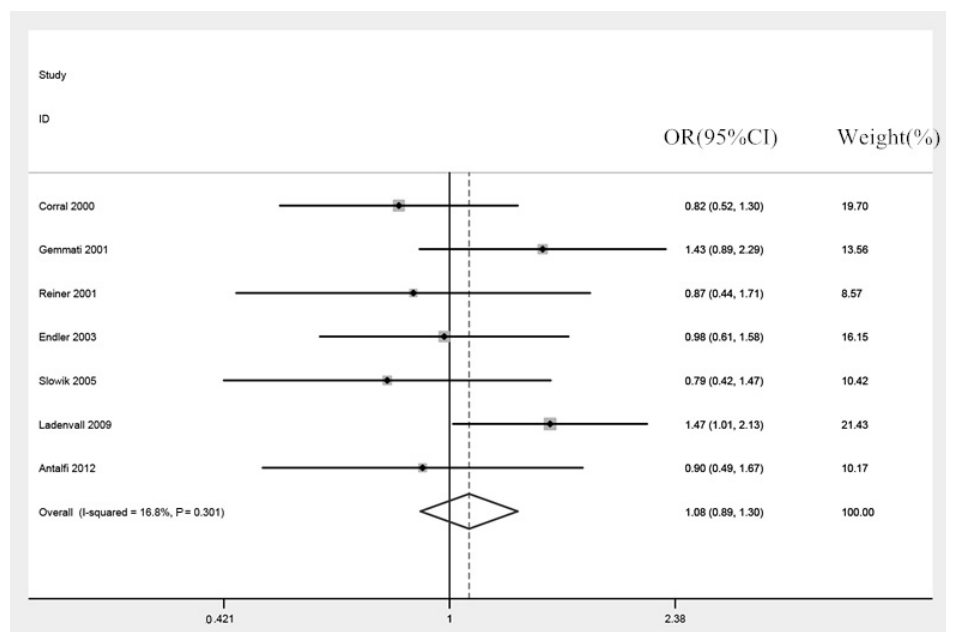

Figure 3. Association between the FXIII-A Val34Leu polymorphism and ICH risk (Val/Leu $v s$ Val/Val).

Genetics and Molecular Research 15 (3): gmr.15038327 


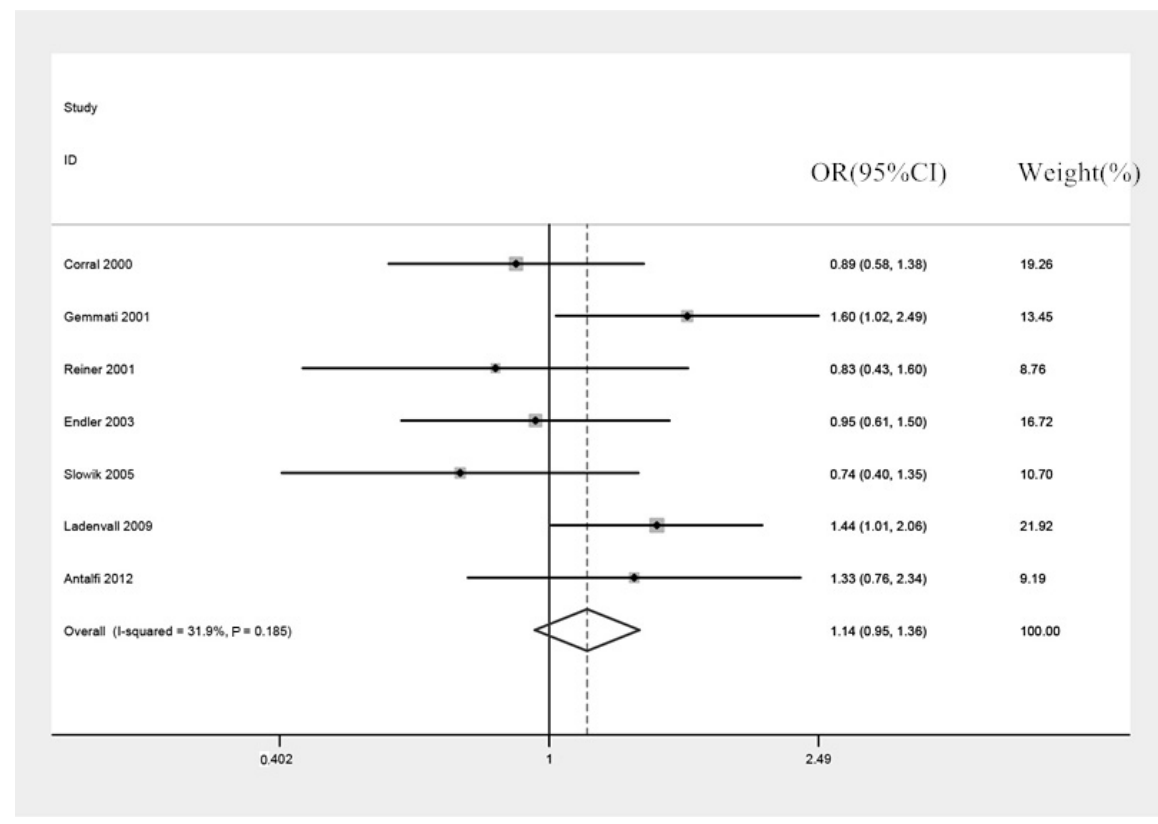

Figure 4. Association between the FXIII-A Val34Leu polymorphism and ICH risk (dominant model).

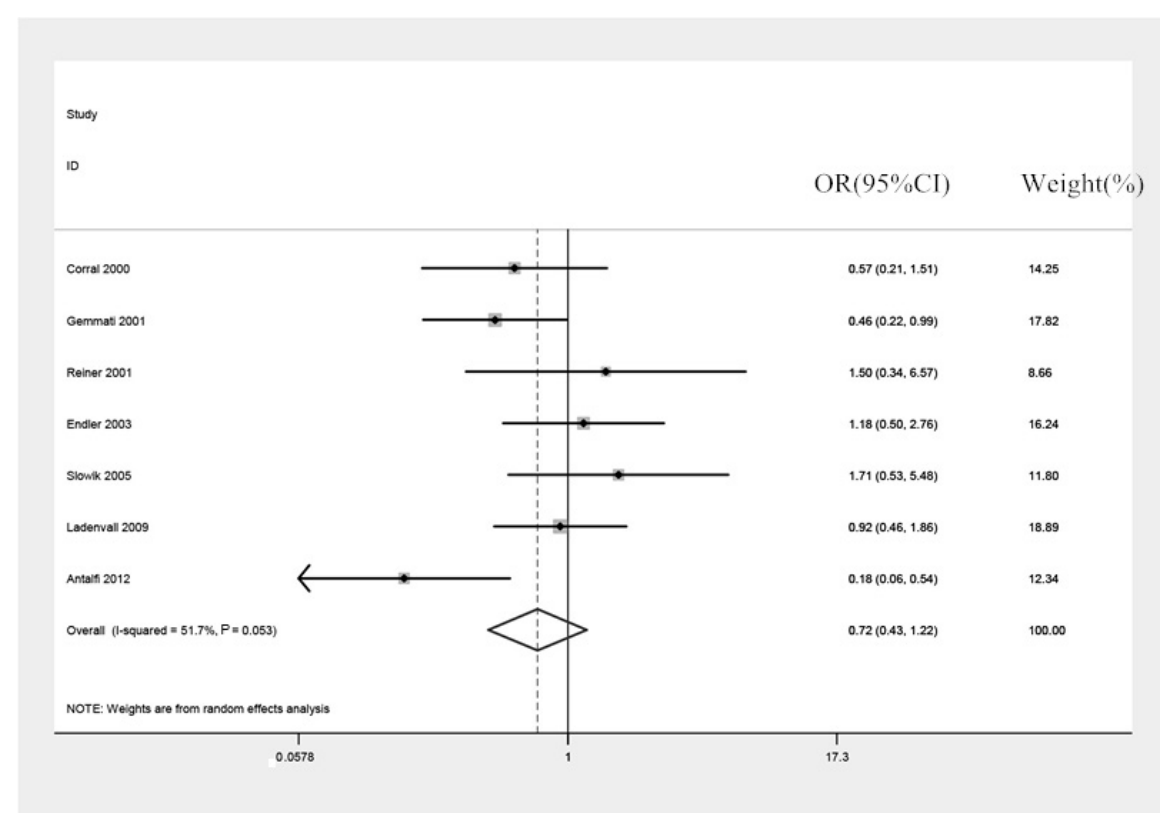

Figure 5. Association between the FXIII-A Val34Leu polymorphism and ICH risk (recessive model).

Genetics and Molecular Research 15 (3): gmr.15038327 


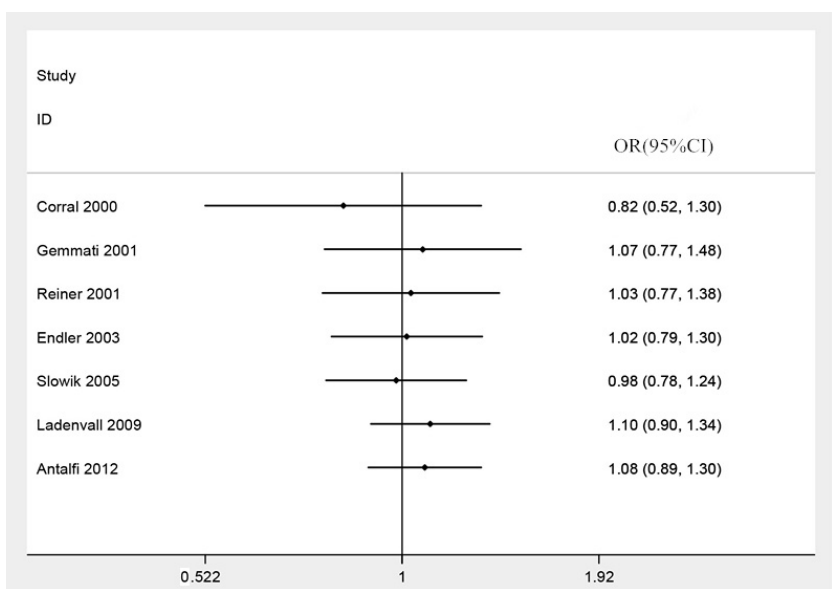

Figure 6. Cumulative meta-analysis of the association between the FXIII-A Val34Leu polymorphism and ICH.

Table 2. Summary odds ratios (ORs) and 95\% confidence intervals (CIs) of the FXIII-A Val34Leu polymorphism
and intracerebral hemorrhage risk.
\begin{tabular}{l|l|c|c|c|c}
\hline Genetic model & Type of model & \multicolumn{2}{c}{ Test of heterogeneity } & \multicolumn{2}{c}{ Test of association } \\
\cline { 3 - 6 } & & $I^{2}$ & $\mathrm{P}$ & OR & $95 \% \mathrm{CI}$ \\
\hline Leu/Leu $v s \mathrm{Val} / \mathrm{Val}$ & Random & $52.7 \%$ & 0.05 & 1.41 & $0.82-2.43$ \\
\hline Val/Leu $v s \mathrm{Val} / \mathrm{Val}$ & Fixed & $31.9 \%$ & 0.30 & 1.08 & $0 . .89-1.30$ \\
\hline Dominant model & Fixed & $51.7 \%$ & 0.19 & 1.14 & $0.95-1.36$ \\
\hline Recessive model & Random &
\end{tabular}

\section{Publication bias}

The publication bias in the articles included in the meta-analysis was analyzed by plotting a Begg's funnel plot. The shape of the funnel plot showed no evidence of publication bias (Figure 7).

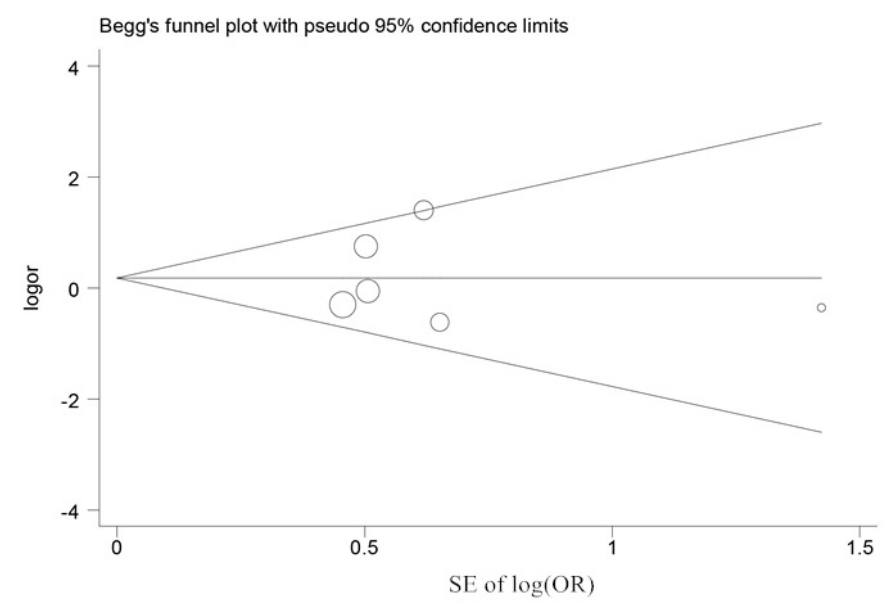

Figure 7. Publication bias for the association between the FXIII-A Val34Leu polymorphism and ICH risk.

Genetics and Molecular Research 15 (3): gmr.15038327 


\section{DISCUSSION}

ICH is a major public health concern, and is responsible for high mortality and disability rates in adults. FXIII plays a crucial role in the blood coagulation and fibrinolytic pathways. Mutations in FXIII could affect their function, and may be associated with ICH risk. The FXIII-A Val34Leu polymorphism resulting from a G-to-T point mutation in codon 34 of exon 2 leads to the substitution of valine with leucine. An increasing number of studies have focused on the relationship between the FXIII-A Val34Leu polymorphism and cardiovascular and cerebrovascular diseases; additionally, previous meta-analyses have indicated that this variant may be a preventive factor against coronary artery disease and venous thromboembolism (Wells et al., 2006; Vokó et al., 2007). A number of recent studies have focused on the association between the Val34Leu polymorphism and ICH, the results of which are controversial. Therefore, this meta-analysis was designed to draw a precise conclusion regarding the association between the FXIII-A Val34Leu polymorphism and ICH risk.

To the best of our knowledge, this is the first meta-analysis to assess the relationship between the FXIII-A Val34Leu polymorphism and ICH risk comprehensively. This metaanalysis, performed using seven relevant studies comprising $727 \mathrm{ICH}$ cases and 1968 controls, explored the association between the Val34Leu polymorphism in FXIII- $A$ and ICH risk. The results of this meta-analysis reveal that the FXIII-A Val34Leu polymorphism is not associated with increased or decreased risk of ICH in Caucasian subjects. The FXIII Val34Leu polymorphism was detected in $44.3 \%$ Caucasians and $2.5 \%$ Asians in a recent study (Attié-Castro et al., 2000). Other studies reported a complete absence or very low prevalence of the FXIII-A Val34Leu polymorphism in Asian subjects (Kangsadalampai and Board, 1998; Cho et al., 2002). Therefore, no relevant publications involving for Asian subjects were included in the final meta-analysis. Further investigations with larger sample populations of Asians are required to clarify the possible effects of this polymorphism on ICH risk.

The results of this meta-analysis were subject to certain limitations. Firstly, the influence of heterogeneity on this type of analysis must be noted. The random-effect model, which assumes that different studies show substantial diversity, and which assesses the sampling errors within the study as well as the between-study variance, was used to minimize the influence of heterogeneity on our results. In addition, the sample sizes of a proportion of included studies were relatively small, and the matching criteria for the cases and controls were not strictly adhered to. Therefore, some bias may persist in these results. The possible associations of sampling bias should be addressed by conducting further investigations with larger sample sizes and strict matching criteria. Finally, the effects of potential gene-gene and gene-environment interactions have not been addressed in this meta-analysis.

In summary, the results of our meta-analysis suggest the FXIII-A Val34Leu polymorphism is not associated with ICH risk. Further studies considering the gene-gene and gene-environment interactions could clarify and reinforce of our understanding of this association.

\section{Conflicts of interest}

The authors declare no conflict of interest.

Genetics and Molecular Research 15 (3): gmr.15038327 


\section{REFERENCES}

Ammar M, Bouazizi F, Bouhaha R, Zaraa I, et al. (2012). Association analysis of LCE3C-LCE3B deletion in Tunisian psoriatic population. Arch. Dermatol. Res. 304: 733-738. http://dx.doi.org/10.1007/s00403-012-1279-4

Antalfi B, Pongrácz E, Csiki Z, Mezei ZA, et al. (2013). Factor XIII-A subunit Val34Leu polymorphism in fatal hemorrhagic stroke. Int. J. Lab. Hematol. 35: 88-91. http://dx.doi.org/10.1111/j.1751-553X.2012.01465.x

Attié-Castro FA, Zago MA, Lavinha J, Elion J, et al. (2000). Ethnic heterogeneity of the factor XIII Val34Leu polymorphism. Thromb. Haemost. 84: 601-603.

Catto AJ, Kohler HP, Bannan S, Stickland M, et al. (1998). Factor XIII Val 34 Leu: a novel association with primary intracerebral hemorrhage. Stroke 29: 813-816. http://dx.doi.org/10.1161/01.STR.29.4.813

Cho KH, Kim BC, Kim MK and Shin BA (2002). No association of factor XIII Val34Leu polymorphism with primary intracerebral hemorrhage and healthy controls in Korean population. J. Korean Med. Sci. 17: 249-253. http://dx.doi. org/10.3346/jkms.2002.17.2.249

Corral J, Iniesta JA, González-Conejero R, Villalón M, et al. (2000). Factor XIII Val34Leu polymorphism in primary intracerebral haemorrhage. Hematol. J. 1: 269-273. http://dx.doi.org/10.1038/sj.thj.6200043

Endler G, Funk M, Haering D, Lalouschek W, et al. (2003). Is the factor XIII 34Val/Leu polymorphism a protective factor for cerebrovascular disease? Br. J. Haematol. 120: 310-314. http://dx.doi.org/10.1046/j.1365-2141.2003.04047.x

Feigin VL, Lawes CM, Bennett DA, Barker-Collo SL, et al. (2009). Worldwide stroke incidence and early case fatality reported in 56 population-based studies: a systematic review. Lancet Neurol. 8: 355-369. http://dx.doi.org/10.1016/ $\underline{\text { S1474-4422(09)70025-0 }}$

Gemmati D, Serino ML, Ongaro A, Tognazzo S, et al. (2001). A common mutation in the gene for coagulation factor XIII-A (VAL34Leu): a risk factor for primary intracerebral hemorrhage is protective against atherothrombotic diseases. Am. J. Hematol. 67: 183-188. http://dx.doi.org/10.1002/ajh.1104

Hsieh L and Nugent D (2008). Factor XIII deficiency. Haemophilia 14: 1190-1200. http://dx.doi.org/10.1111/j.13652516.2008.01857.x

Jagiełła J, Dardiotis E, Gąsowski J, Pera J, et al. (2014). The FGA Thr312Ala polymorphism and risk of intracerebral haemorrhage in Polish and Greek populations. Neurol. Neurochir. Pol. 48: 105-110. http://dx.doi.org/10.1016/j. pjnns.2013.12.004

Kangsadalampai S and Board PG (1998). The Val34Leu polymorphism in the A subunit of coagulation factor XIII contributes to the large normal range in activity and demonstrates that the activation peptide plays a role in catalytic activity. Blood 92: 2766-2770.

Ladenvall C, Csajbok L, Nylén K, Jood K, et al. (2009). Association between factor XIII single nucleotide polymorphisms and aneurysmal subarachnoid hemorrhage. J. Neurosurg. 110: 475-481. http://dx.doi.org/10.3171/2008.7.JNS08272

Lau J, Ioannidis JP and Schmid CH (1997). Quantitative synthesis in systematic reviews. Ann. Intern. Med. 127: 820-826. http://dx.doi.org/10.7326/0003-4819-127-9-199711010-00008

Li B, Zhang L, Yin Y, Pi Y, et al. (2012). Lack of evidence for association between factor XIII-A Val34Leu polymorphism and ischemic stroke: a meta-analysis of 8,800 subjects. Thromb. Res. 130: 654-660. http://dx.doi.org/10.1016/j. thromres.2011.11.030

Lovelock CE, Molyneux AJ and Rothwell PM; Oxford Vascular Study (2007). Change in incidence and aetiology of intracerebral haemorrhage in Oxfordshire, UK, between 1981 and 2006: a population-based study. Lancet Neurol. 6: 487-493. http://dx.doi.org/10.1016/S1474-4422(07)70107-2

Mikkola H, Syrjälä M, Rasi V, Vahtera E, et al. (1994). Deficiency in the A-subunit of coagulation factor XIII: two novel point mutations demonstrate different effects on transcript levels. Blood 84: 517-525.

Nugent DJ (2006). Prophylaxis in rare coagulation disorders - factor XIII deficiency. Thromb. Res. 118 (Suppl 1): S23-S28. http://dx.doi.org/10.1016/j.thromres.2006.02.009

Perez DL, Diamond EL, Castro CM, Diaz A, et al. (2011). Factor XIII deficiency related recurrent spontaneous intracerebral hemorrhage: a case and literature review. Clin. Neurol. Neurosurg. 113: 142-145. http://dx.doi.org/10.1016/j. clineuro.2010.09.003

Qureshi AI, Mendelow AD and Hanley DF (2009). Intracerebral haemorrhage. Lancet 373: 1632-1644. http://dx.doi. org/10.1016/S0140-6736(09)60371-8

Reiner AP, Schwartz SM, Frank MB, Longstreth Jr WT, et al. (2001). Polymorphisms of coagulation factor XIII subunit A and risk of nonfatal hemorrhagic stroke in young white women. Stroke 32: 2580-2586. http://dx.doi.org/10.1161/ hs1101.098150

Slowik A, Dziedzic T, Pera J, Figlewicz DA, et al. (2005). Coagulation factor XIII VaI34Leu polymorphism in patients with small vessel disease or primary intracerebral hemorrhage. Cerebrovasc. Dis. 19: 165-170. http://dx.doi.

Genetics and Molecular Research 15 (3): gmr.15038327 
org/10.1159/000083251

Sturgeon JD, Folsom AR, Longstreth Jr WT, Shahar E, et al. (2007). Risk factors for intracerebral hemorrhage in a pooled prospective study. Stroke 38: 2718-2725. http://dx.doi.org/10.1161/STROKEAHA.107.487090

Vokó Z, Bereczky Z, Katona E, Adány R, et al. (2007). Factor XIII Val34Leu variant protects against coronary artery disease. A meta-analysis. Thromb. Haemost. 97: 458-463.

Wang G, Zou Z, Ji X, Ni Q, et al. (2014). Factor XIII-A Val34Leu polymorphism might beassociated with myocardial infarction risk: an updated meta-analysis. Int. J. Clin. Exp. Med. 7: 5547-5552.

Wells PS, Anderson JL, Scarvelis DK, Doucette SP, et al. (2006). Factor XIII Val34Leu variant is protective against venous thromboembolism: a HuGE review and meta-analysis. Am. J. Epidemiol. 164: 101-109. http://dx.doi. org/10.1093/aje/kwj179

Woo D, Falcone GJ, Devan WJ, Brown WM, et al.; International Stroke Genetics Consortium (2014). Meta-analysis of genome-wide association studies identifies 1q22 as a susceptibility locus for intracerebral hemorrhage. Am. J. Hum. Genet. 94: 511-521. http://dx.doi.org/10.1016/j.ajhg.2014.02.012

Zintzaras E and Lau J (2008). Synthesis of genetic association studies for pertinent gene-disease associations requires appropriate methodological and statistical approaches. J. Clin. Epidemiol. 61: 634-645. http://dx.doi.org/10.1016/j. jclinepi.2007.12.011

Genetics and Molecular Research 15 (3): gmr.15038327 